Supporting Information

\title{
DNA nanoswitch barcodes for multiplexed biomarker profiling
}

\author{
Arun Richard Chandrasekaran, ${ }^{1 *}$ Molly Maclsaac, ${ }^{2,3,4}$ Javier Vilcapoma, ${ }^{1}$ \\ Clinton H. Hansen, 2,3,4 Darren Yang, 2,3,4 Wesley P. Wong, ${ }^{2,3,4 *}$ and Ken Halvorsen ${ }^{\text {* }}$ \\ 1The RNA Institute, University at Albany, State University of New York, New York, NY, USA. \\ 2Program in Cellular and Molecular Medicine, Boston Children's Hospital, Boston, MA 02115. \\ 3Wyss Institute for Biologically Inspired Engineering, Harvard University, Boston, MA 02115. \\ ${ }^{4}$ Department of Biological Chemistry and Molecular Pharmacology, Blavatnik Institute, Harvard \\ Medical School, Boston, MA 02115.
}

Email: arun@albany.edu, wesley.wong@childrens.harvard.edu, khalvorsen@albany.edu 


\section{MATERIALS AND METHODS}

\section{Materials}

Oligonucleotides (including RNA, biotin-modified DNA and digoxygenin-modified DNA) were purchased from Integrated DNA Technologies (IDT) with standard desalting. M13 circular DNA and BtsCl enzymes were purchased from New England Biolabs (NEB). GelRed nucleic acid stain was purchased from Biotium, Fremont, CA, USA. Molecular biology grade agarose was purchased from Fisher BioReagents.

\section{Linearization of M13 DNA}

$5 \mu \mathrm{l}$ of $100 \mathrm{nM}$ circular single-stranded M13 DNA, $2.5 \mu \mathrm{l}$ of $10 \times$ Cut Smart buffer, $0.5 \mu \mathrm{l}$ of $100 \mu \mathrm{M} \mathrm{BtsCl}$ restriction-site complementary-oligonucleotide and $16 \mu \mathrm{l}$ of deionized water were mixed and annealed from $95^{\circ} \mathrm{C}$ to $50^{\circ} \mathrm{C}$ in a T100 тм Thermal Cycler (Bio-Rad, Hercules, CA, USA). $1 \mu$ of the BtsCl enzyme $(20,000$ units $/ \mathrm{ml})$ was added to the mixture and incubated at $50^{\circ} \mathrm{C}$ for $15 \mathrm{~min}$. The mixture was brought up to $95^{\circ} \mathrm{C}$ for $1 \mathrm{~min}$ to heat deactivate the enzyme followed by cooling down to $4{ }^{\circ} \mathrm{C}$.

\section{Antibody coupling}

Antibodies were coupled to oligonucleotides as previously described (Hansen et al, PNAS 2017, 114, 10367-10372). In brief, sandwiching antibodies against PSA (Medix Biochemica Anti-h PSA 8301 and Anti-h PSA 8311) were buffer exchanged in 1× PBS using two Zeba columns (Thermo Fisher Scientific) to remove storage sodium azide. $60 \mu \mathrm{L}$ of washed PSA antibodies at $\sim 4.0 \mu \mathrm{M}$ were mixed with an equimolar amount of DBCO-PEG4-NHS ester linker (Sigma) in 40 mM, pH 8.6 HEPES buffer and incubated at room temperature for $30 \mathrm{~min}$. Then, 5-fold excess of azide-modified oligonucleotides (Integrated DNA technologies) were added and incubated for $90 \mathrm{~min}$ at room temperature. Antibodyoligo conjugates were then purified from excess oligonucleotides and linkers using the Thunder-Link Conjugate Clean Up Reagent (Innova Biosciences) and resuspended in $40 \mu \mathrm{L}$ of $1 \times$ PBS. Antibody coupling and purification were confirmed using 4-20\% TBE polyacrylamide gels (Bio-Rad) stained with Krypton Fluorescent Protein Stain (Thermo Fisher Scientific). 


\section{Construction of nanoswitches}

For genotyping, biotin and digoxygenin nanoswitches, linearized single-stranded M13 DNA (20 nM) was mixed with 10-fold excess of the backbone oligonucleotides and detector strands and annealed from $90{ }^{\circ} \mathrm{C}$ to $20^{\circ} \mathrm{C}$ at $1^{\circ} \mathrm{C} \mathrm{min}{ }^{-1}$ in a thermal cycler. Following construction, the nanoswitches were purified using HPLC to remove excess oligonucleotides or used unpurified after dilution in $1 \times$ PBS to a concentration of 400 pM. For PSA nanoswitches, linearized single-stranded M13 DNA (20 nM) was mixed with 10 -fold excess of the backbone oligonucleotides and annealed from $90{ }^{\circ} \mathrm{C}$ to $20{ }^{\circ} \mathrm{C}$ at $1{ }^{\circ} \mathrm{C}$ $\min ^{-1}$ in a thermal cycler. 80-fold excess of the conjugated antibody-oligonucleotide detectors were added when the hybridization protocol reached $37^{\circ} \mathrm{C}$. Following construction, the nanoswitches were purified with BluePippin using $0.75 \%$ agarose, $1-50 \mathrm{~kb}$ gel cassette (Sage Science) to remove excess oligonucleotides and antibody-oligo conjugates. The PSA nanoswitches were stored undiluted in protein lobind tubes (Eppendorf) at $4{ }^{\circ} \mathrm{C}$.

\section{Nanoswitch characterization}

A typical reaction contained 160 pM nanoswitch with 2.5 nM DNA targets in a $10 \mu \mathrm{l}$ reaction. Samples were incubated at room temperature for $1 \mathrm{~h}$. For sensitivity experiment, the target DNA was spiked into a $500 \mathrm{nM}$ solution of off-target "blocking" oligos to minimize loss to the tubes. Microcentrifuge tubes and pipette tips were additionally pre-incubated in blocking oligo solution to minimize loss of the target DNA. The nanoswitch/DNA target solution was incubated overnight at $20^{\circ} \mathrm{C}$ in a solution containing $1 \times$ PBS and $10 \mathrm{mM} \mathrm{MgCl}_{2}$. For specificity experiments, the final concentration of target strands were $2.5 \mathrm{nM}$ and incubation time was $1 \mathrm{~h}$ at $20^{\circ} \mathrm{C}$ in a solution containing $1 \times \mathrm{PBS}$. For the time series experiment (Figure S5), we performed the reaction in reverse, starting with the longest time point followed by shorter time points until time 0 . Samples were mixed with gel stain and loading dye, and immediately loaded in gels. For detecting double stranded DNA, the duplexes were heated at $90^{\circ} \mathrm{C}$ for 3 minutes and added to DNA nanoswitches, and incubated at $20^{\circ} \mathrm{C}$ for $1 \mathrm{~h}$.

\section{Nanoswitch barcode operation for gene identification and biomarker detection}

Nanoswitch mixture was prepared by mixing equimolar amounts of individual nanoswitches (6 nanoswitches for multiplexed gene analysis and 4 nanoswitches for mixed multiplexing). For barcoded detection, a typical reaction contained final concentrations of $\sim 160 \mathrm{pM}$ nanoswitch mixture, $1 \times$ PBS and $2.5 \mathrm{nM}$ single stranded DNA corresponding to gene fragments. For barcodes of mixed biomarkers, typical concentrations were $\sim 1 \mathrm{nM}$ anti-digoxygenin, $\sim 0.8 \mathrm{nM}$ RNA, $\sim 2 \mathrm{nM}$ DNA and $\sim 0.8 \mathrm{nM}$ streptavidin. For concentration series, different concentrations of the biomarkers were added as indicated in Figure 4 and Figure S9. 


\section{Biomarker panel detection in serum}

Nanoswitch mixture was prepared by mixing miR-30c, PSA, and miR-141 nanoswitches to a final molar ratio of $1: 2: 3$ respectively. EDTA was added to $20 \%$ FBS to a final concentration of $100 \mathrm{mM}$. For serum detection, a typical $11 \mu \mathrm{L}$ reaction contained $6 \mu \mathrm{L}$ of $20 \%$ FBS with $100 \mathrm{mM}$ EDTA, biomarkers at a final concentration of $2.5 \mathrm{nM}, 1 \times \mathrm{PBS}$, and $2 \mu \mathrm{L}$ of nanoswitch mixture (final concentrations of $30 \mathrm{pM}, 60 \mathrm{pM}$, and $90 \mathrm{pM}$ ). The biomarkers used were PSA antigen (Biospacific, cat\#: J63011, high purity) and ssDNA sequences of miR-141 and miR-30c (Integrated DNA technologies). Samples were incubated at room temperature for 90 minutes.

\section{Multiplexed sensitivity test}

Nanoswitch mixture was prepared by mixing PSA and miR-141 nanoswitches (of different loop sizes) to a final molar ratio of 1:2 respectively. Final reaction volume of $15 \mu$ l contained $3 \mu$ l nanoswitch mixture

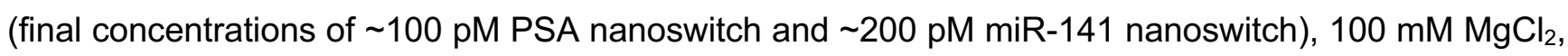
$1 \times$ PBS, 95 pM PSA and varying concentrations of miR-141 (Figure S11). Target microRNA was spiked into a $500 \mathrm{nM}$ solution of off-target "blocking" oligos to minimize loss to the tubes. Microcentrifuge tubes and pipette tips were additionally pre-incubated in blocking oligo solution to minimize loss of the target microRNA. Samples were incubated overnight at $20^{\circ} \mathrm{C}$. Samples were pre-stained by mixing $1 \times$ GelRed stain and a Ficoll based loading dye (15\% Ficoll, $0.1 \%$ bromophenol blue) before loading. $10 \mu \mathrm{l}$ of the samples was loaded and run on an unstained agarose gel.

\section{Gel electrophoresis}

Nanoswitches were run in $0.8 \%$ agarose gels, cast from molecular biology grade agarose dissolved in $0.5 \times$ Tris-borate EDTA (TBE). Characterization gels of individual nanoswitches were typically run at 75 $\mathrm{V}$ (constant voltage) at room temperature and barcode gels (multiplexing) were run at $55 \mathrm{~V}$ (constant voltage) at $4{ }^{\circ} \mathrm{C}$. Samples were pre-stained by mixing $1 \times$ GelRed stain and a Ficoll based loading dye with the samples before loading. $10 \mu \mathrm{l}$ of the samples were loaded and run on an unstained agarose gel. Gels were imaged with a Bio-Rad Gel Doc XR+ gel imager and analyzed using ImageJ. For the prostate cancer biomarker panel, nanoswitches were run in $0.8 \%$ agarose gels at $70 \mathrm{~V}$ (constant voltage) at room temperature. After incubation, samples were diluted by adding $1 \times$ volume of $0.5 \times$ TBE. Samples were then pre-stained with $1 \times$ GelRed stain and a Ficoll based loading dye (Promega) and $0.25 \mu \mathrm{L}$ of $1 \%$ Coomassie Brilliant Blue G-250 were added before loading. Gels were imaged with an Invitrogen iBright FL1000 Imaging System and analyzed using ImageJ. Median filter in ImageJ was used to remove noise in gel images in Figure 5c. 

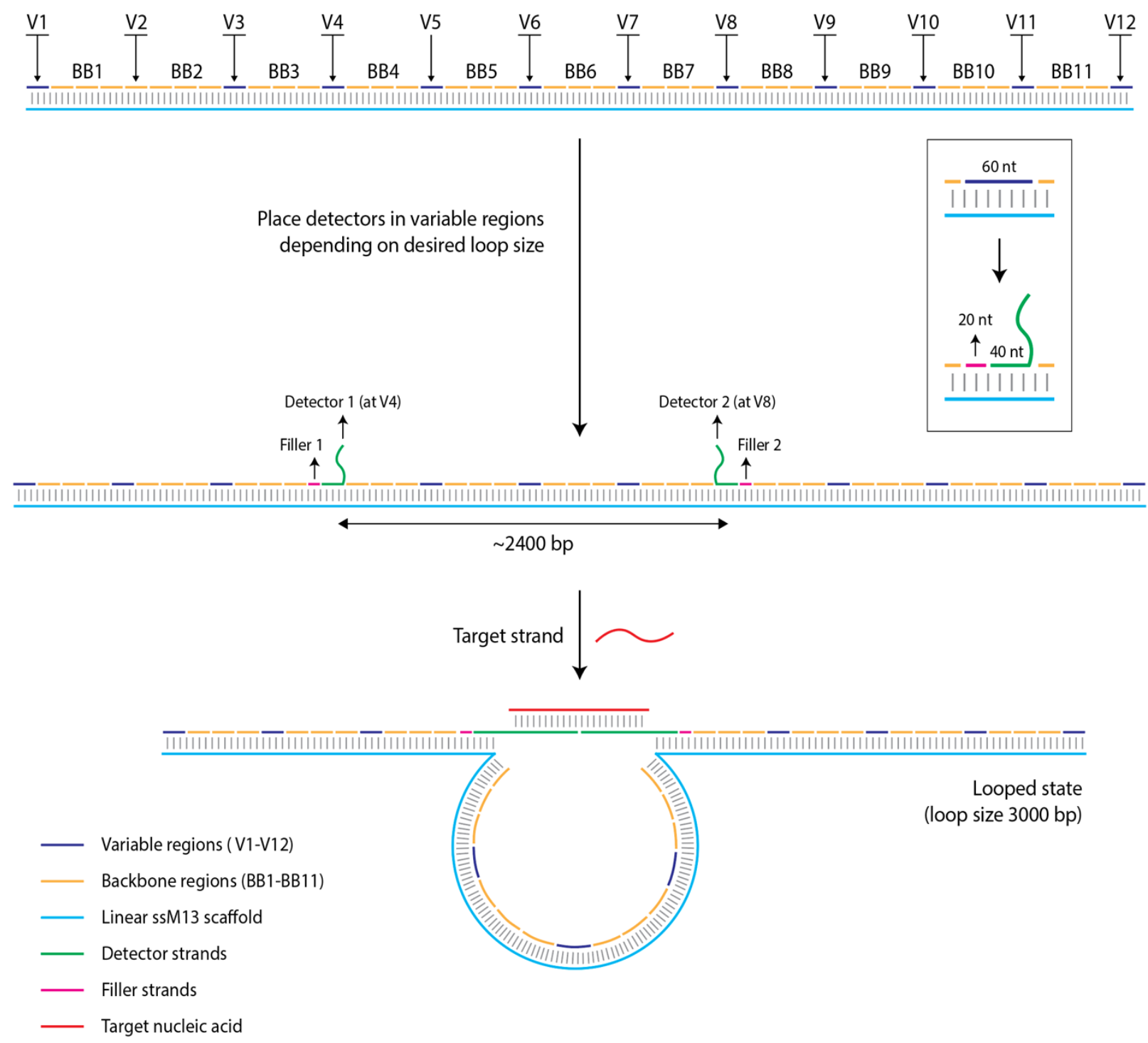

Figure S1. The nanoswitch is a duplex formed from linear M13 and short complementary backbone oligonucleotides. Twelve regions (60 nt each) are designated as "variable" regions. Two detectors containing single-stranded overhangs that complement the target can be inserted in place of two of the variable regions. The distance between the two detectors dictates the loop size and migration of the looped state on a gel. 


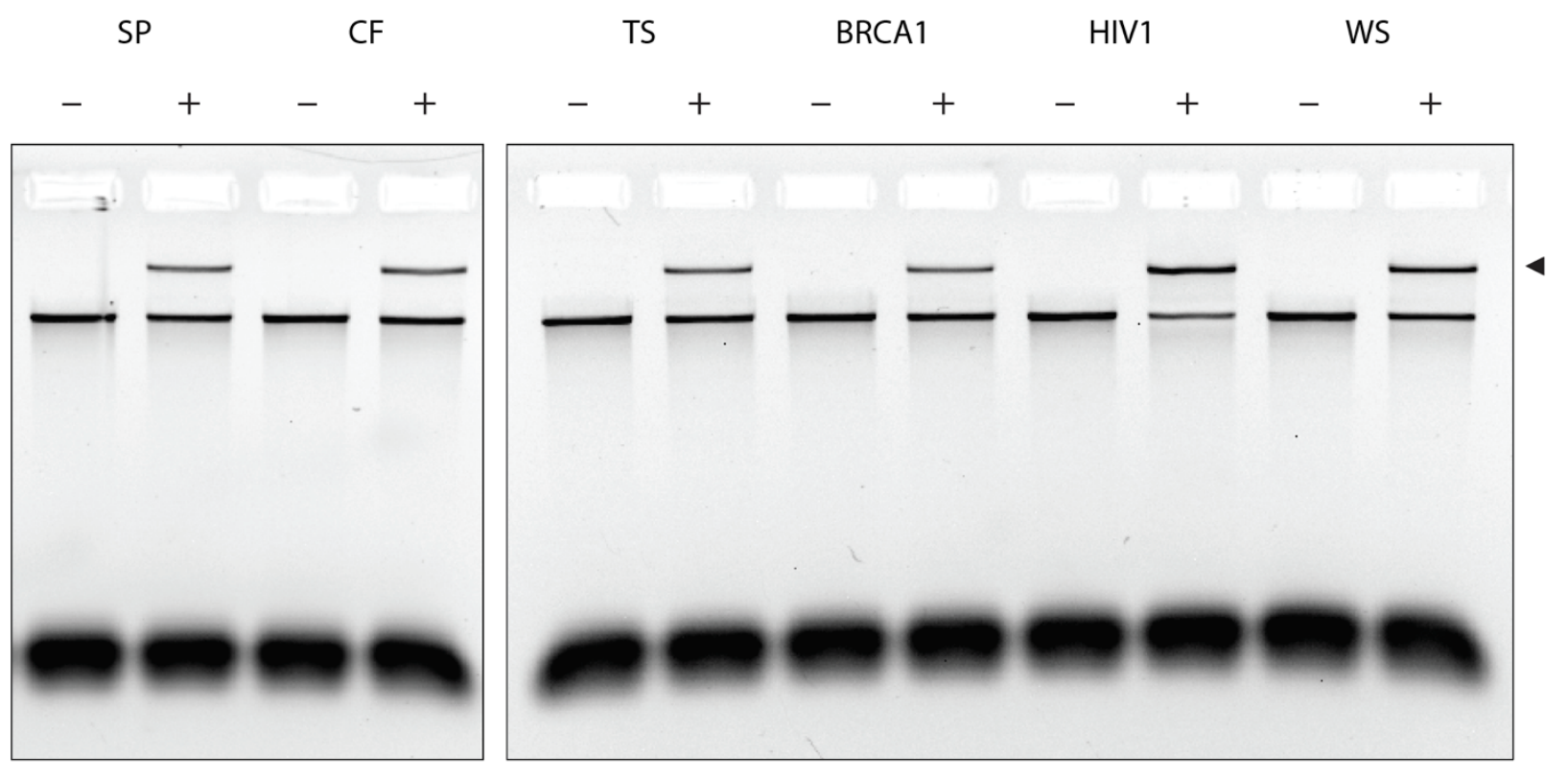

Figure S2. Detection of different gene fragments using DNA nanoswitches. Gel shown here is the full image of the gel shown in Figure $2 \mathrm{~b}$. 


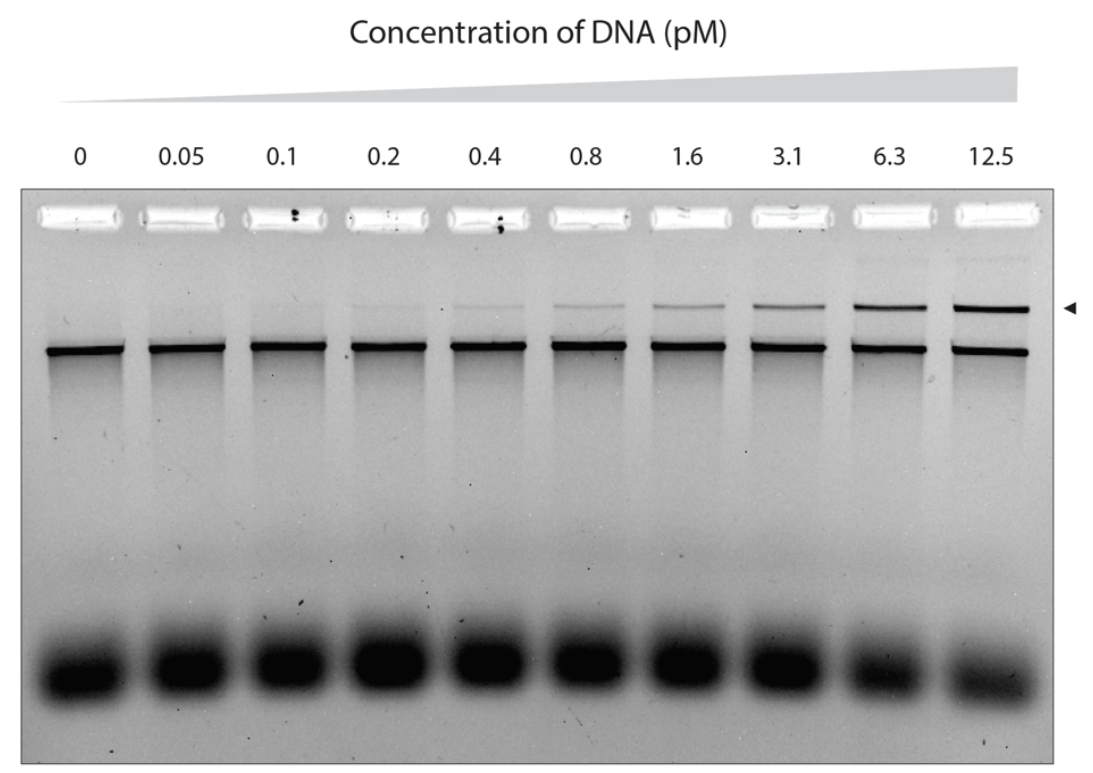

Figure S3. Sensitivity of DNA nanoswitch assay for cystic fibrosis gene fragment. Full image of gel shown in Figure 2c. 


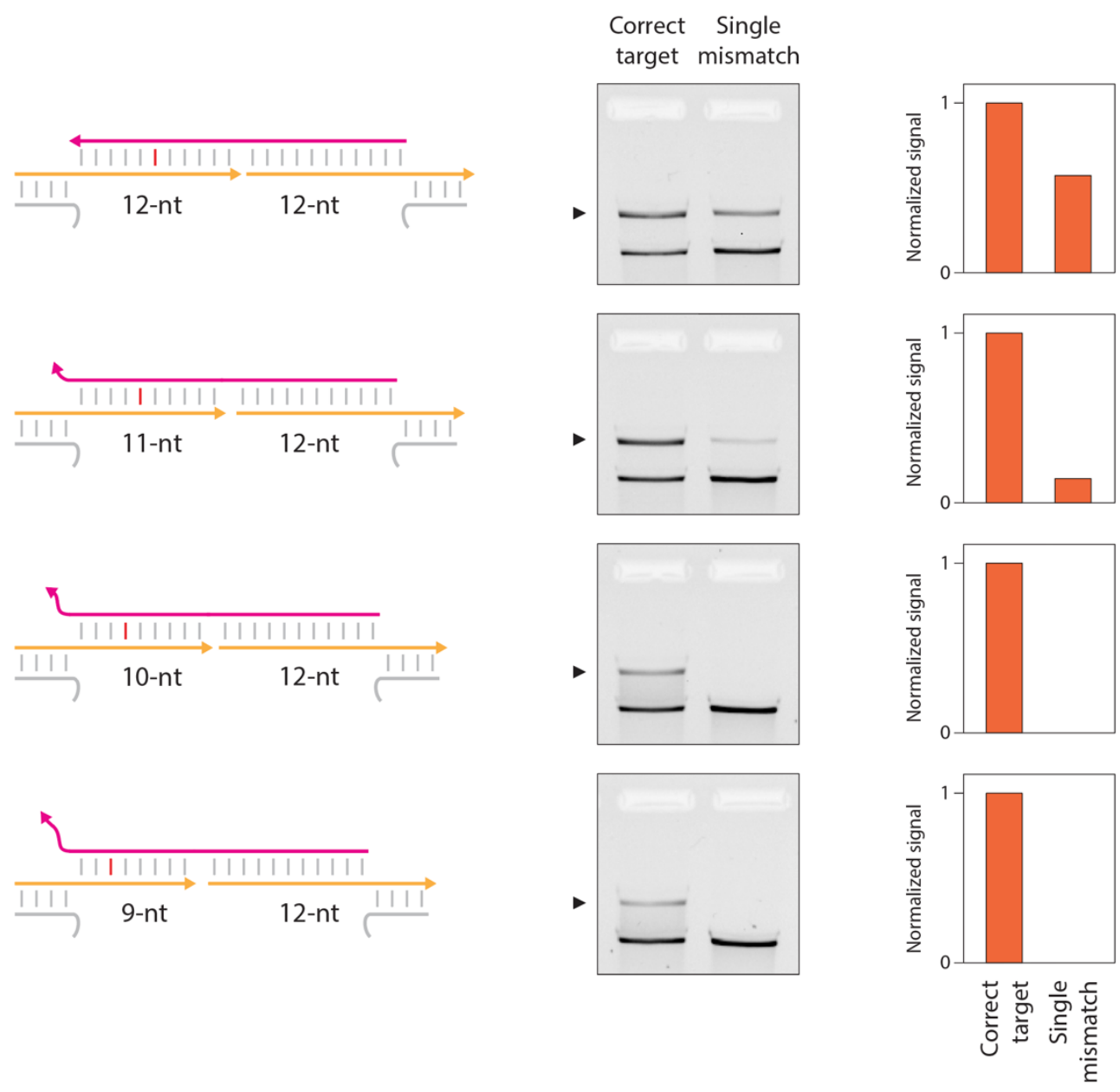

Figure S4. Specificity of DNA nanoswitch assay demonstrated with cystic fibrosis gene fragment. With detector length that complements the whole target sequence, a single mismatched target yielded $40 \%$ signal compared to a correctly matched target. On reducing the length of the detector, the specificity to discriminate a single mismatch increased, with no signal for the mismatched target using 10-nt and 9nt detector length. The 9-nt detector length was used for the specificity image shown in Figure $2 \mathrm{~d}$. 
a

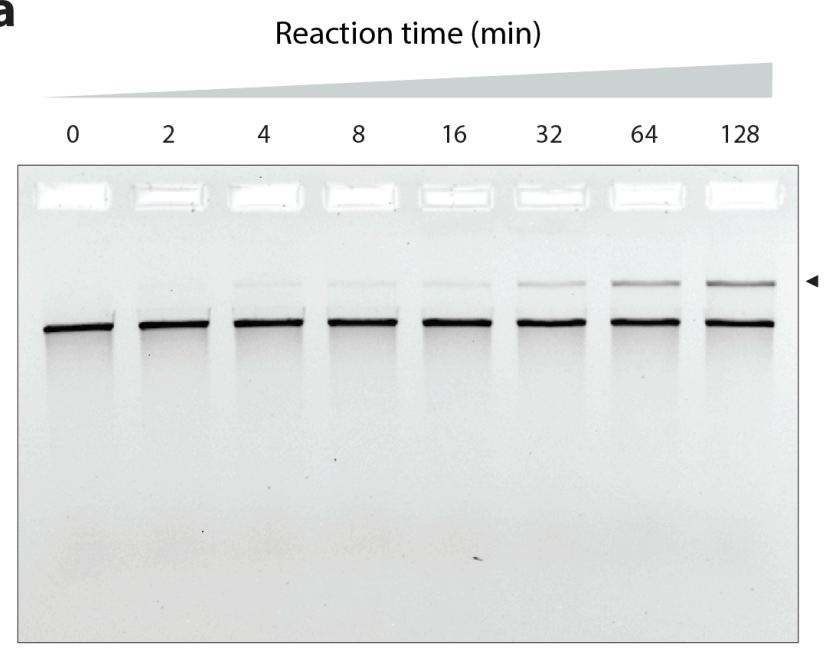

b

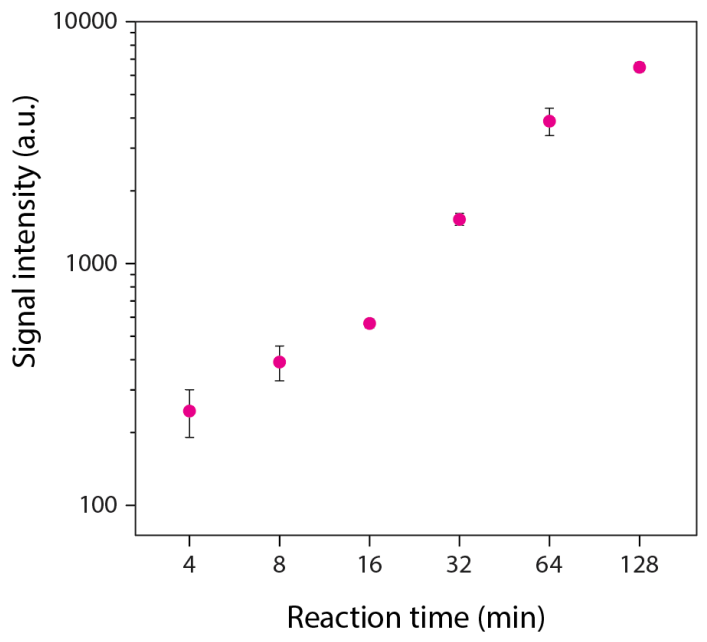

Figure S5. Time series of detection of a $1 \mathrm{nM}$ cystic fibrosis gene fragment. 
a

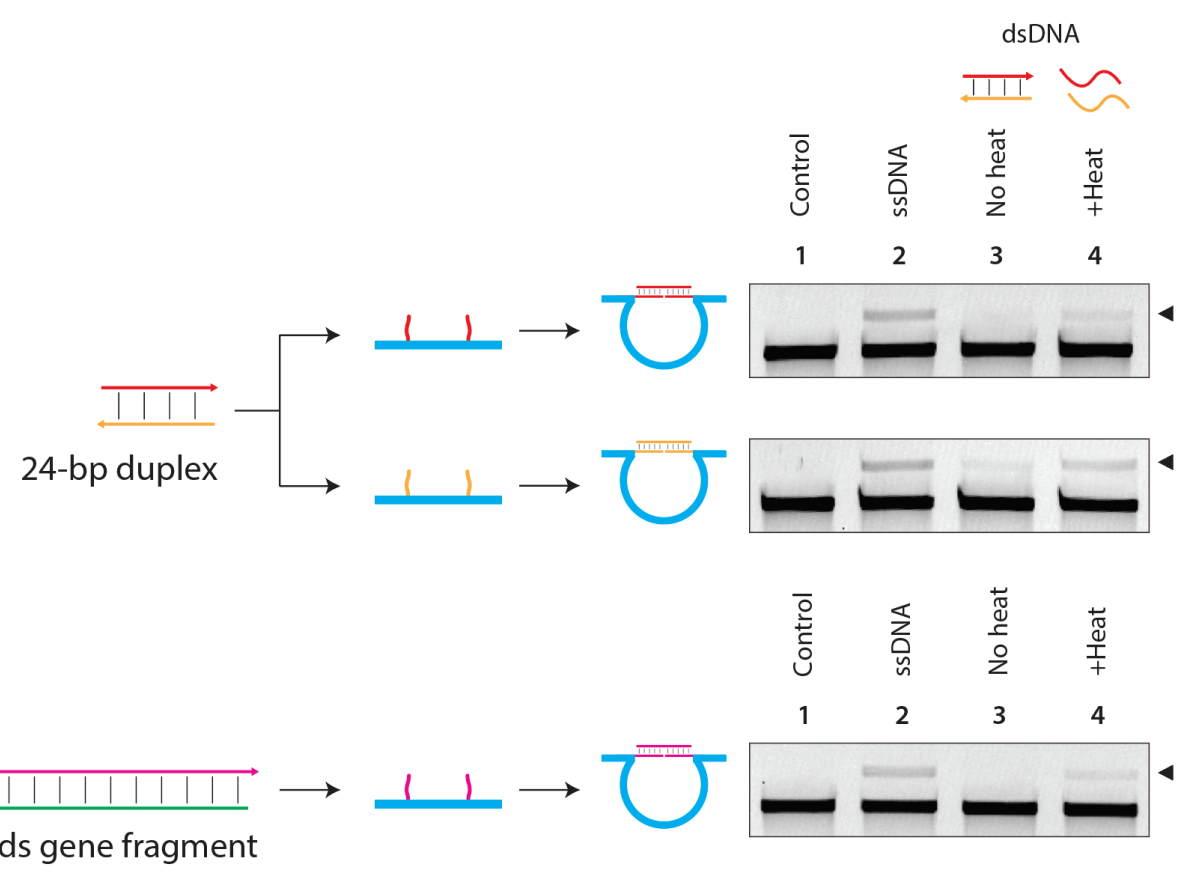

Figure S6. Detection of double stranded fragments using DNA nanoswitches. (a) Detection of each strand of a 24-bp duplex using corresponding DNA nanoswitches. (b) Detection from a double stranded 125-bp cystic fibrosis gene fragment. 

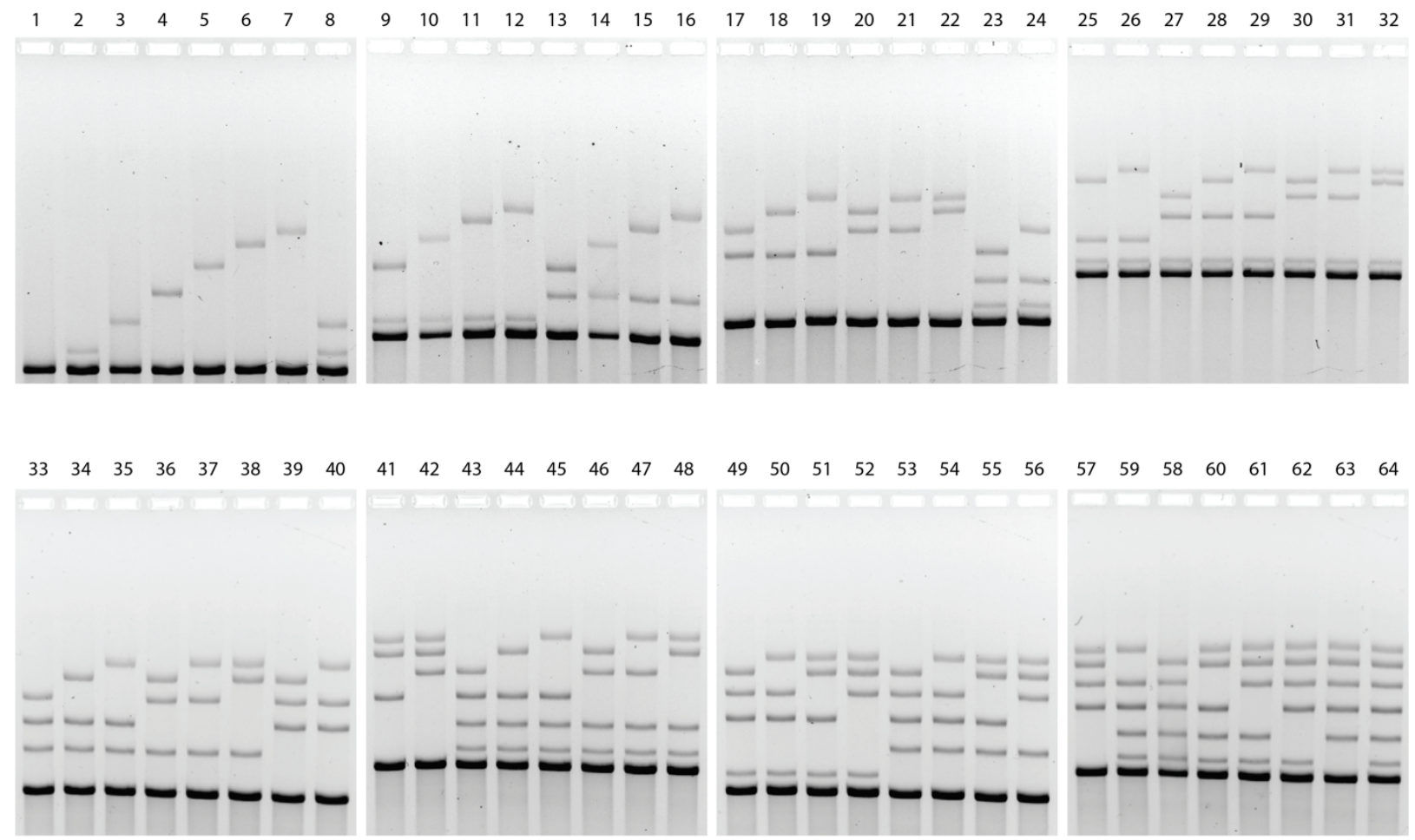

Figure S7. Full set of DNA nanoswitch gene barcodes. Gel images show all combinations of six different gene fragments. Full gel images of results shown in Figure 3d. 


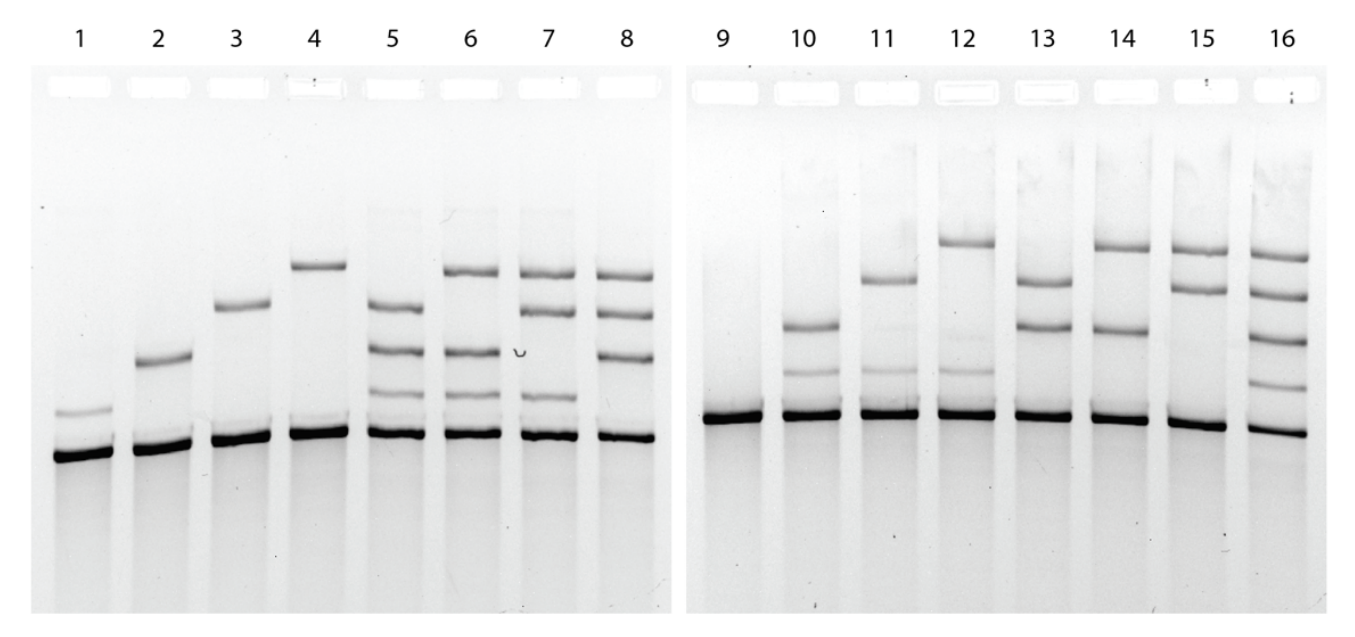

Figure S8. Full set of DNA nanoswitch barcodes for multiplexed detection of different types of biomarkers (anti-digoxygenin antibody, RNA, DNA and streptavidin). Full gel images of results shown in Figure 4e. 

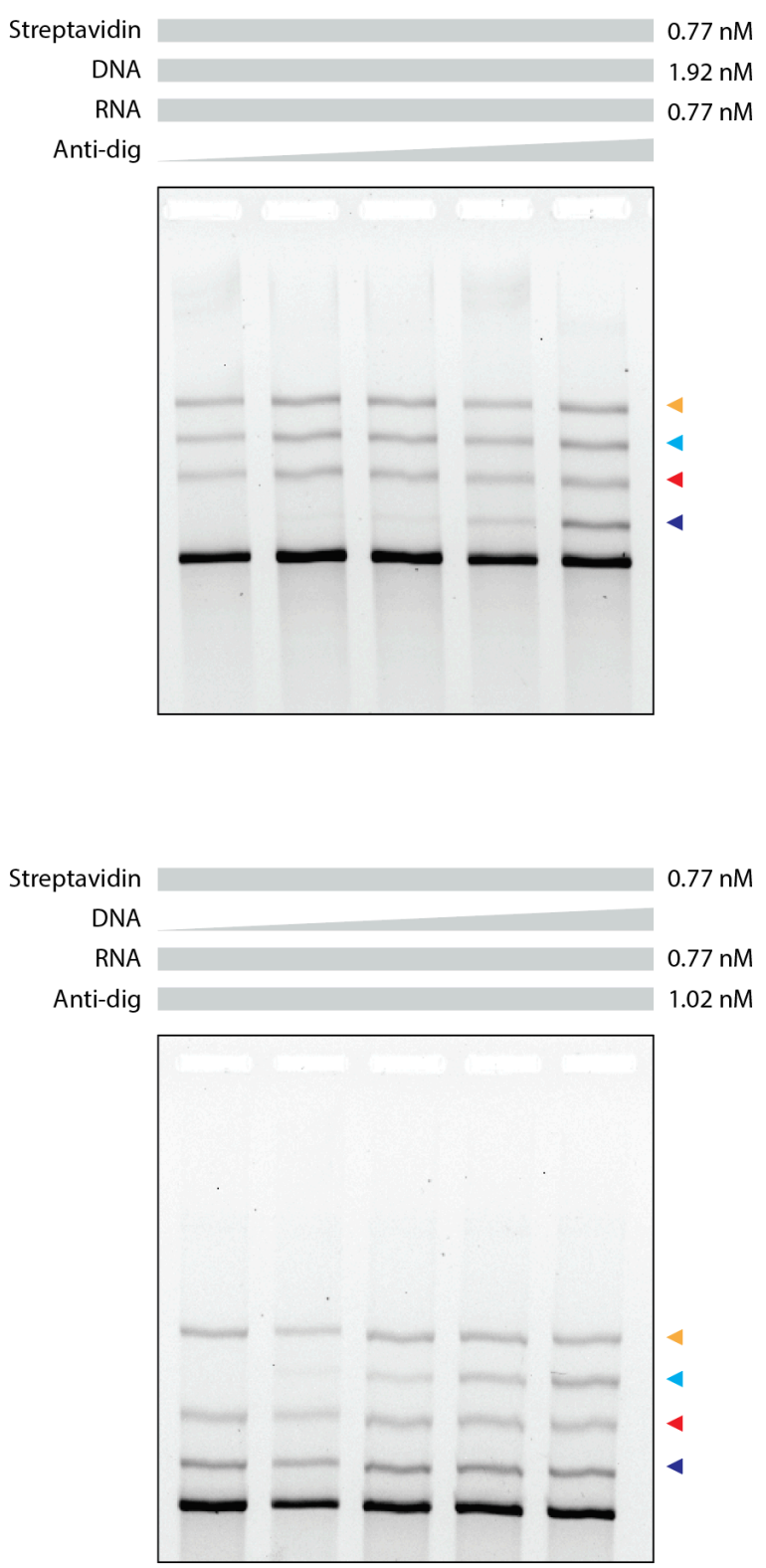
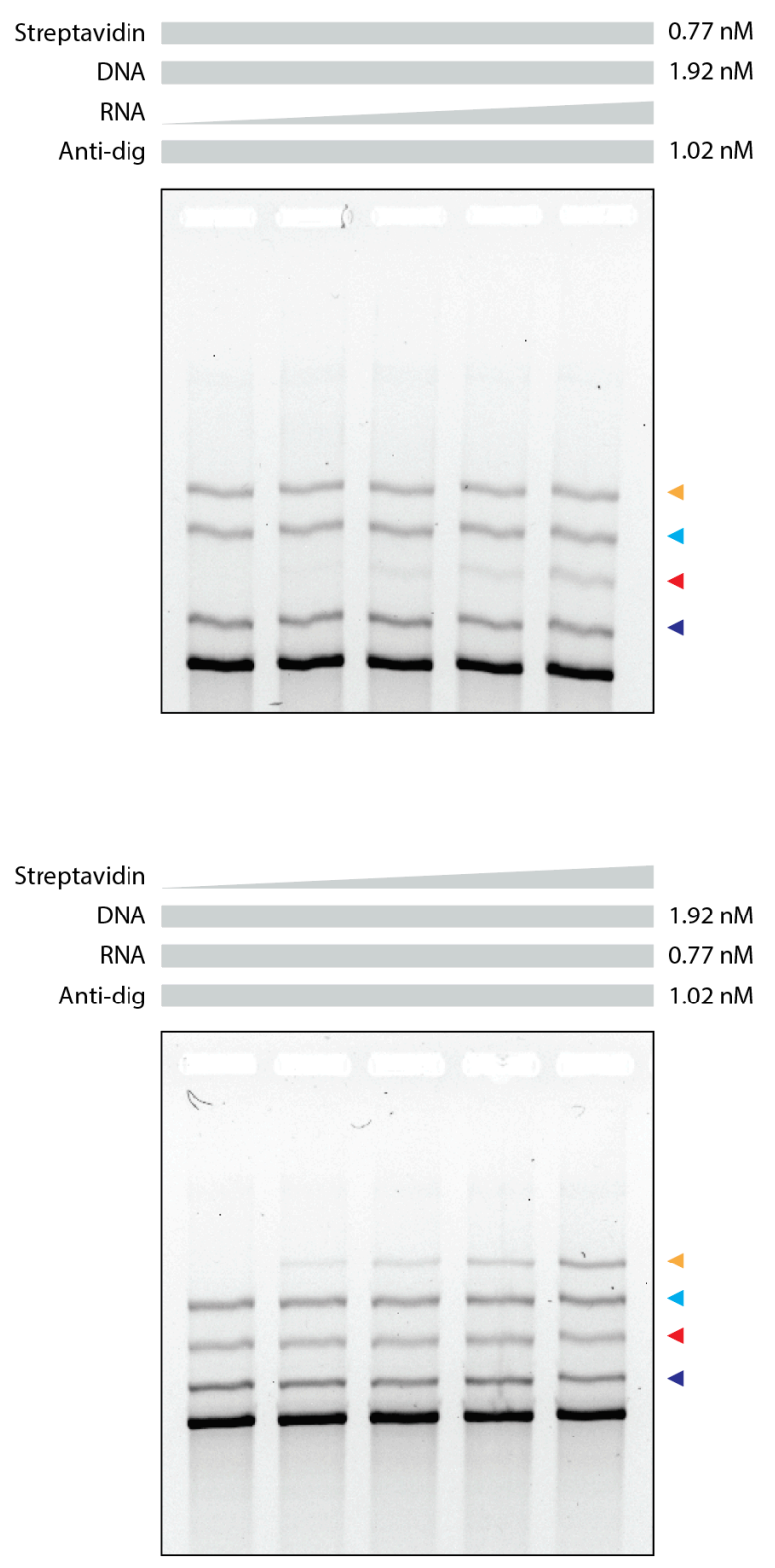

Figure S9. Multiplexed concentration series of different biomarkers. Full gel images of results shown in Figure 4f. Constant concentrations of target molecules are indicated above the gel images. The varying concentrations of a single target is shown in Figure $4 \mathrm{f}$ and Figure $\mathrm{S} 10$. 

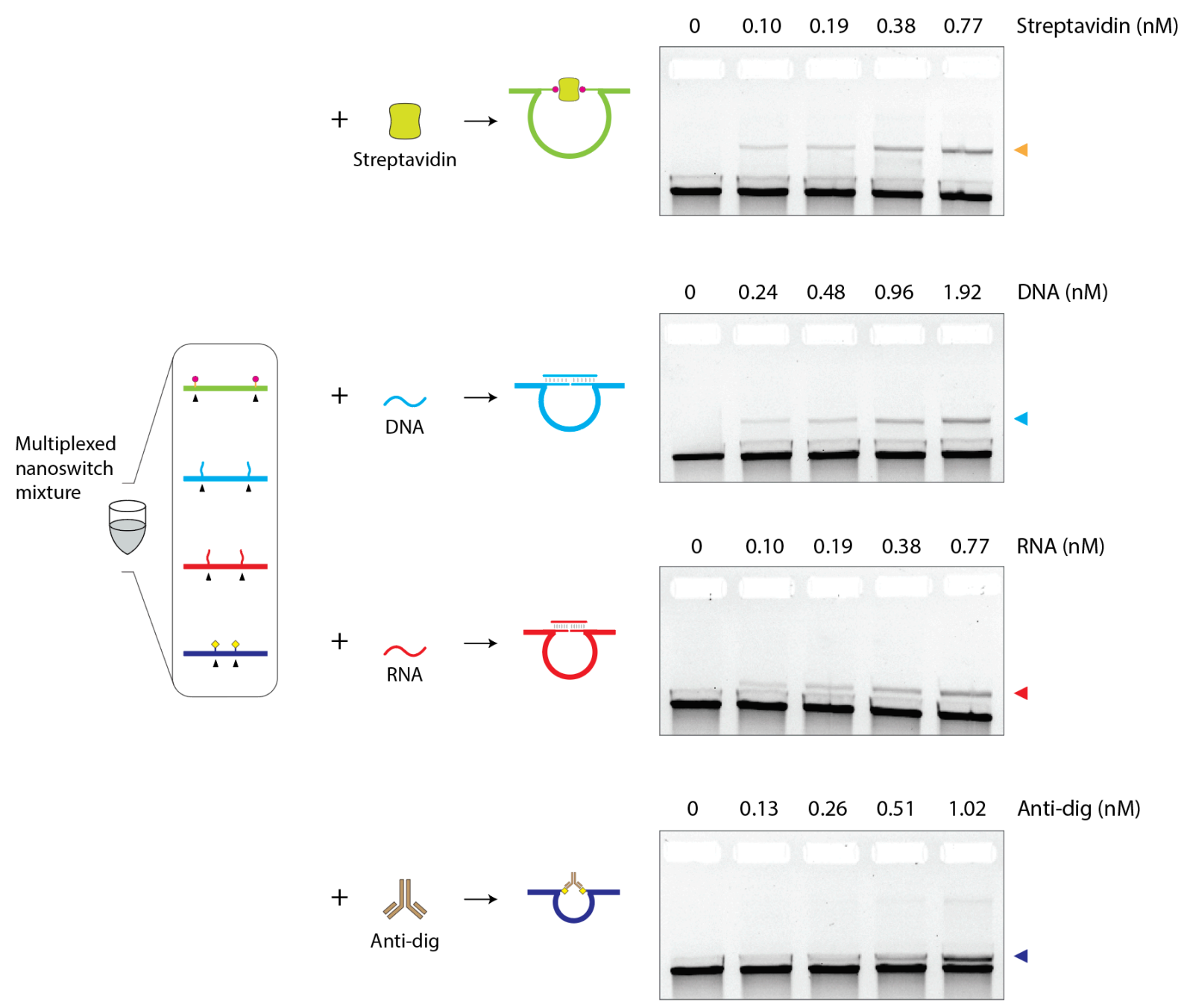

Figure S10. Concentration series of individual biomarkers using a nanoswitch mix. 


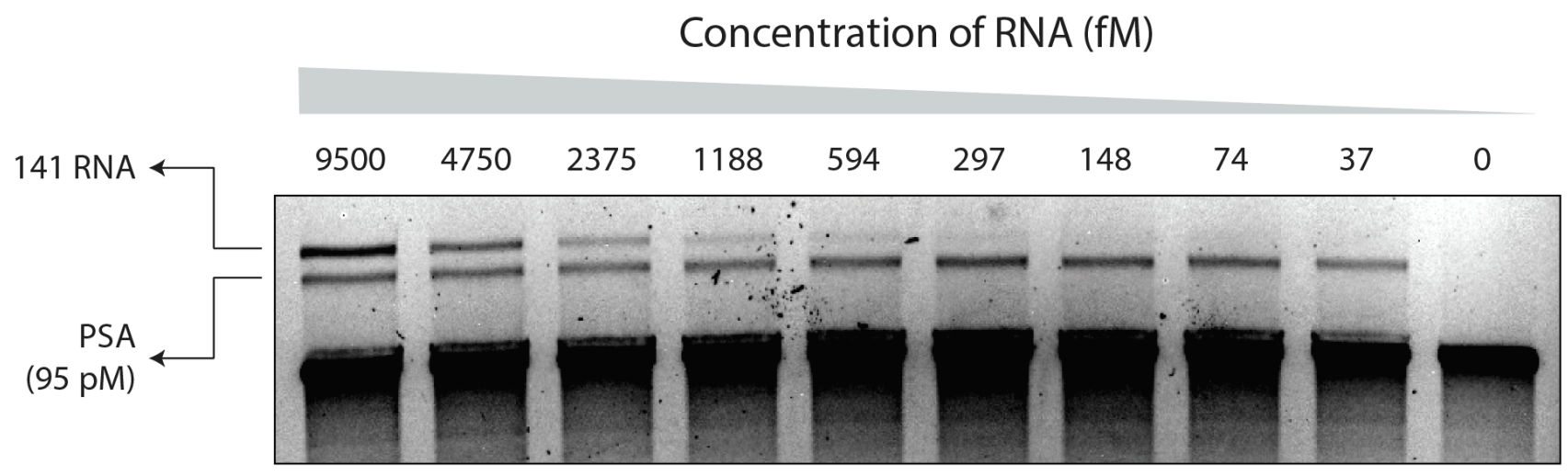

Figure S11. Clinical level sensitivity of microRNA 141 (varying concentrations) and PSA ( 95 pM) in a multiplexed assay. 

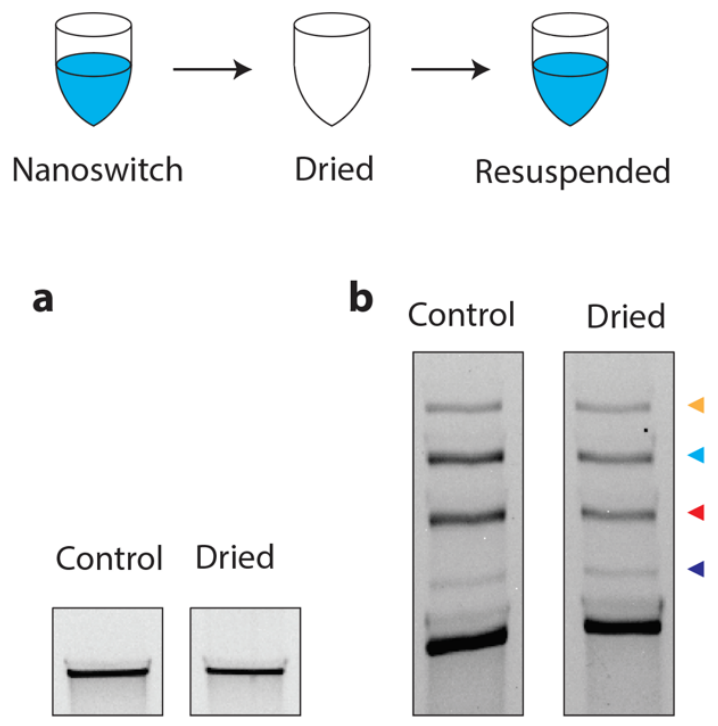

Figure S12. Stability and functionality of dried nanoswitches. (a) Nanoswitch mix is stable after drying and resuspending. (b) A dried and resuspended nanoswitch mixture can detect the four different target biomolecules. 
Complete list of all sequences used. All sequences are written from 5' to 3'.

\begin{tabular}{|c|c|c|}
\hline \multicolumn{3}{|c|}{ Backbone oligonucleotides } \\
\hline BB\# & Sequence & Length \\
\hline 1 & AGAGCATAAAGCTAAATCGGTTGTACCAAAAACATTATGACCCTGTAATACTTTTGCGGG & 60 \\
\hline 2 & AGAAGCCTTTATTTCAACGCAAGGATAAAAATTTTTAGAACCCTCATATATTTTAAATGC & 60 \\
\hline 3 & AATGCCTGAGTAATGTGTAGGTAAAGATTCAAAAGGGTGAGAAAGGCCGGAGACAGTCAA & 60 \\
\hline 4 & ATCACCATCAATATGATATTCAACCGTTCTAGCTGATAAATTAATGCCGGAGAGGGTAGC & 60 \\
\hline 5 & TATTTTTGAGAGATCTACAAAGGCTATCAGGTCATTGCCTGAGAGTCTGGAGCAAACAAG & 60 \\
\hline 6 & AGAATCGATGAACGGTAATCGTAAAACTAGCATGTCAATCATATGTACCCCGGTTGATAA & 60 \\
\hline 7 & TCAGAAAAGCCCCAAAAACAGGAAGATTGTATAAGCAAATATTTAAATTGTAAACGTTAA & 60 \\
\hline 8 & TATTTTGTTAAAATTCGCATTAAATTTTTGTTAAATCAGCTCATTTTTTAACCAATAGGA & 60 \\
\hline 9 & ACGCCATCAAAAATAATTCGCGTCTGGCCTTCCTGTAGCCAGCTTTCATCAACATTAAAT & 60 \\
\hline 10 & GGATAGGTCACGTTGGTGTAGATGGGCGCATCGTAACCGTGCATCTGCCAGTTTGAGGGG & 60 \\
\hline 11 & ACGACGACAGTATCGGCCTCAGGAAGATCGCACTCCAGCCAGCTTTCCGGCACCGCTTCT & 60 \\
\hline 12 & GGTGCCGGAAACCAGGCAAAGCGCCATTCGCCATTCAGGCTGCGCAACTGTTGGGAAGGG & 60 \\
\hline 13 & CGATCGGTGCGGGCCTCTTCGCTATTACGCCAGCTGGCGAAAGGGGGATGTGCTGCAAGG & 60 \\
\hline 14 & CGATTAAGTTGGGTAACGCCAGGGTTTTCCCAGTCACGACGTTGTAAAACGACGGCCAGT & 60 \\
\hline 15 & GCCAAGCTTGCATGCCTGCAGGTCGACTCTAGAGGATCCCCGGGTACCGAGCTCGAATTC & 60 \\
\hline 16 & GTAATCATGGTCATAGCTGTTTCCTGTGTGAAATTGTTATCCGCTCACAATTCCACACAA & 60 \\
\hline 17 & CATACGAGCCGGAAGCATAAAGTGTAAAGCCTGGGGTGCCTAATGAGTGAGCTAACTCAC & 60 \\
\hline 18 & ATTAATTGCGTTGCGCTCACTGCCCGCTTTCCAGTCGGGAAACCTGTCGTGCCAGCTGCA & 60 \\
\hline 19 & TTAATGAATCGGCCAACGCGCGGGGAGAGGCGGTTTGCGTATTGGGCGCCAGGGTGGTTT & 60 \\
\hline 20 & GTTGCAGCAAGCGGTCCACGCTGGTTTGCCCCAGCAGGCGAAAATCCTGTTTGATGGTGG & 60 \\
\hline 21 & TTCCGAAATCGGCAAAATCCCTTATAAATCAAAAGAATAGCCCGAGATAGGGTTGAGTGT & 60 \\
\hline 22 & TGTTCCAGTTTGGAACAAGAGTCCACTATTAAAGAACGTGGACTCCAACGTCAAAGGGCG & 60 \\
\hline 23 & AAAAACCGTCTATCAGGGCGATGGCCCACTACGTGAACCATCACCCAAATCAAGTTTTTT & 60 \\
\hline 24 & GGGGTCGAGGTGCCGTAAAGCACTAAATCGGAACCCTAAAGGGAGCCCCCGATTTAGAGC & 60 \\
\hline 25 & TTGACGGGGAAAGCCGGCGAACGTGGCGAGAAAGGAAGGGAAGAAAGCGAAAGGAGCGGG & 60 \\
\hline 26 & CGCTAGGGCGCTGGCAAGTGTAGCGGTCACGCTGCGCGTAACCACCACACCCGCCGCGCT & 60 \\
\hline 27 & TAATGCGCCGCTACAGGGCGCGTACTATGGTTGCTTTGACGAGCACGTATAACGTGCTTT & 60 \\
\hline 28 & СCTCGTTAGAATCAGAGCGGGAGCTAAACAGGAGGCCGATTAAAGGGATTTTAGACAGGA & 60 \\
\hline 29 & ACGGTACGCCAGAATCCTGAGAAGTGTTTTTATAATCAGTGAGGCCACCGAGTAAAAGAG & 60 \\
\hline 30 & TTGCCTGAGTAGAAGAACTCAAACTATCGGCCTTGCTGGTAATATCCAGAACAATATTAC & 60 \\
\hline 31 & CGCCAGCCATTGCAACAGGAAAAACGCTCATGGAAATACCTACATTTTGACGCTCAATCG & 60 \\
\hline 32 & TCTGAAATGGATTATTTACATTGGCAGATTCACCAGTCACACGACCAGTAATAAAAGGGA & 60 \\
\hline 33 & СATTCTGGCCAACAGAGATAGAACCCTTCTGACCTGAAAGCGTAAGAATACGTGGCACAG & 60 \\
\hline 34 & ACAATATTTTTGAATGGCTATTAGTCTTTAATGCGCGAACTGATAGCCCTAAAACATCGC & 60 \\
\hline 35 & CATTAAAAATACCGAACGAACCACCAGCAGAAGATAAAACAGAGGTGAGGCGGTCAGTAT & 60 \\
\hline 36 & TAACACCGCCTGCAACAGTGCCACGCTGAGAGCCAGCAGCAAATGAAAAATCTAAAGCAT & 60 \\
\hline 37 & САCСTTGCTGAACCTCAAATATCAAACCCTCAATCAATATCTGGTCAGTTGGCAAATCAA & 60 \\
\hline 38 & CAGTTGAAAGGAATTGAGGAAGGTTATCTAAAATATCTTTAGGAGCACTAACAACTAATA & 60 \\
\hline
\end{tabular}




\begin{tabular}{|c|c|c|}
\hline 39 & GATTAGAGCCGTCAATAGATAATACATTTGAGGATTTAGAAGTATTAGACTTTACAAACA & 60 \\
\hline 40 & САTTATCATTTTGCGGAACAAAGAAACCACCAGAAGGAGCGGAATTATCATCATATTCCT & 60 \\
\hline 41 & GATTATCAGATGATGGCAATTCATCAATATAATCCTGATTGTTTGGATTATACTTCTGAA & 60 \\
\hline 42 & TAATGGAAGGGTTAGAACCTACCATATCAAAATTATTTGCACGTAAAACAGAAATAAAGA & 60 \\
\hline 43 & АATTGCGTAGATTTTCAGGTTTAACGTCAGATGAATATACAGTAACAGTACСTTTTACAT & 60 \\
\hline 44 & CGGGAGAAACAATAACGGATTCGCCTGATTGCTTTGAATACCAAGTTACAAAATCGCGCA & 60 \\
\hline 45 & GAGGCGAATTATTCATTTCAATTACCTGAGCAAAAGAAGATGATGAAACAAACATCAAGA & 60 \\
\hline 46 & 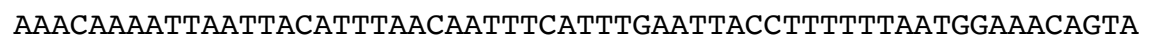 & 60 \\
\hline 47 & САTAAATCAATATATGTGAGTGAATAACCTTGCTTCTGTAAATCGTCGCTATTAATTAAT & 60 \\
\hline 48 & TTTCCCTTAGAATCCTTGAAAACATAGCGATAGCTTAGATTAAGACGCTGAGAAGAGTCA & 60 \\
\hline 49 & АTAGTGAATTTATCAAAATCATAGGTCTGAGAGACTACCTTTTTAACСTCCGGCTTAGGT & 60 \\
\hline 50 & 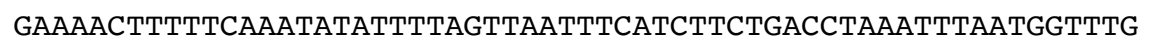 & 60 \\
\hline 51 & AAATACCGACCGTGTGATAAATAAGGCGTTAAATAAGAATAAACACCGGAATCATAATTA & 60 \\
\hline 52 & СTAGAAAAAGCCTGTTTAGTATCATATGCGTTATACAAATTCTTACCAGTATAAAGCCAA & 60 \\
\hline 53 & CGCTCAACAGTAGGGCTTAATTGAGAATCGCCATATTTAACAACGCCAACATGTAATTTA & 60 \\
\hline 54 & GGCAGAGGCATTTTCGAGCCAGTAATAAGAGAATATAAAGTACCGACAAAAGGTAAAGTA & 60 \\
\hline 55 & АTTCTGTCCAGACGACGACAATAAACAACATGTTCAGCTAATGCAGAACGCGCCTGTTTA & 60 \\
\hline 56 & TCAACAATAGATAAGTCCTGAACAAGAAAAATAATATCCCATCCTAATTTACGAGCATGT & 60 \\
\hline 57 & AGAAACCAATCAATAATCGGCTGTCTTTCCTTATCATTCCAAGAACGGGTATTAAACCAA & 60 \\
\hline 58 & GTACCGCACTCATCGAGAACAAGCAAGCCGTTTTTATTTTCATCGTAGGAATCATTACCG & 60 \\
\hline 59 & CGCCCAATAGCAAGCAAATCAGATATAGAAGGCTTATCCGGTATTCTAAGAACGCGAGGC & 60 \\
\hline 60 & АTTTTGCACCCAGCTACAATTTTATCCTGAATCTTACCAACGCTAACGAGCGTCTTTCCA & 60 \\
\hline 61 & GAGCCTAATTTGCCAGTTACAAAATAAACAGCCATATTATTTATCCCAАTCCAAATAAGA & 60 \\
\hline 62 & AACGATTTTTTGTTTAACGTCAAAAATGAAAATAGCAGCCTTTACAGAGAGAATAACATA & 60 \\
\hline 63 & AAAACAGGGAAGCGCATTAGACGGGAGAATTAACTGAACACCCTGAACAAAGTCAGAGGG & 60 \\
\hline 64 & TAATTGAGCGCTAATATCAGAGAGATAACCCACAAGAATTGAGTTAAGCCCAATAATAAG & 60 \\
\hline 65 & AGCAAGAAACAATGAAATAGCAATAGCTATCTTACCGAAGCCCTTTTTAAGAAAAGTAAG & 60 \\
\hline 66 & CAGATAGCCGAACAAAGTTACCAGAAGGAAACCGAGGAAACGCAATAATAACGGAATACC & 60 \\
\hline 67 & CAAAAGAACTGGCATGATTAAGACTCCTTATTACGCAGTATGTTAGCAAACGTAGAAAAT & 60 \\
\hline 68 & ACATACATAAAGGTGGCAACATATAAAAGAAACGCAAAGACACCACGGAATAAGTTTATT & 60 \\
\hline 69 & TTGTCACAATCAATAGAAAATTCATATGGTTTACCAGCGCCAAAGACAAAAGGGCGACAT & 60 \\
\hline 70 & TCACCGTCACCGACTTGAGCCATTTGGGAATTAGAGCCAGCAAAATCACCAGTAGCACCA & 60 \\
\hline 71 & TTACCATTAGCAAGGCCGGAAACGTCACCAATGAAACCATCGATAGCAGCACCGTAATCA & 60 \\
\hline 72 & GTAGCGACAGAATCAAGTTTGCCTTTAGCGTCAGACTGTAGCGCGTTTTCATCGGCATTT & 60 \\
\hline 73 & TCGGTCATAGCCCCCTTATTAGCGTTTGCCATCTTTTCATAATCAAAATCACCGGAACCA & 60 \\
\hline 74 & GAGCCACCACCGGAACCGCCTCCCTCAGAGCCGCCACCCTCAGAACCGCCACCCTCAGAG & 60 \\
\hline 75 & CCACCACCCTCAGAGCCGCCACCAGAACCACCACCAGAGCCGCCGCCAGCATTGACAGGA & 60 \\
\hline 76 & GGTTGAGGCAGGTCAGACGATTGGCCTTGATATTCACAAACAAATAAATCCTCATTAAAG & 60 \\
\hline 77 & CCAGAATGGAAAGCGCAGTCTCTGAATTTACCGTTCCAGTAAGCGTCATACATGGCTTTT & 60 \\
\hline 78 & GATGATACAGGAGTGTACTGGTAATAAGTTTTAACGGGGTCAGTGCCTTGAGTAACAGTG & 60 \\
\hline 79 & CCCGTATAAACAGTTAATGCCCCCTGCCTATTTCGGAACCTATTATTCTGAAACATGAAA & 60 \\
\hline 80 & CCAGGCGGATAAGTGCCGTCGAGAGGGTTGATATAAGTATAGCCCGGAATAGGTGTATCA & 60 \\
\hline 81 & CCGTACTCAGGAGGTTTAGTACCGCCACCCTCAGAACCGCCACCCTCAGAACCGCCACCC & 60 \\
\hline
\end{tabular}




\begin{tabular}{|c|c|c|}
\hline 82 & TCAGAGCCACCACCCTCATTTTCAGGGATAGCAAGCCCAATAGGAACCCATGTACCGTAA & 60 \\
\hline 83 & САCTGAGTTTCGTCACCAGTACAAACTACAACGCCTGTAGCATTCCACAGACAGCCCTCA & 60 \\
\hline 84 & TAGTTAGCGTAACGATCTAAAGTTTTGTCGTCTTTCCAGACGTTAGTAAATGAATTTTCT & 60 \\
\hline 85 & GTATGGGATTTTGCTAAACAACTTTCAACAGTTTCAGCGGAGTGAGAATAGAAAGGAACA & 60 \\
\hline 86 & АСTAAAGGAATTGCGAATAATAATTTTTTCACGTTGAAAATCTCCAAAAAAAAGGCTCCA & 60 \\
\hline 87 & AAAGGAGCCTTTAATTGTATCGGTTTATCAGCTTGCTTTCGAGGTGAATTTCTTAAACAG & 60 \\
\hline 88 & СTTGATACCGATAGTTGCGCCGACAATGACAACAACCATCGCCCACGCATAACCGATATA & 60 \\
\hline 89 & TTCGGTCGCTGAGGCTTGCAGGGAGTTAAAGGCCGCTTTTGCGGGATCGTCACCCTCAGC & 60 \\
\hline 90 & СTTTTTCATGAGGAAGTTTCCATTAAACGGGTAAAATACGTAATGCCACTACGAAGGCAC & 60 \\
\hline 91 & CAACCTAAAACGAAAGAGGCAAAAGAATACACTAAAACACTCATCTTTGACCCCCAGCGA & 60 \\
\hline 92 & TTATACCAAGCGCGAAACAAAGTACAACGGAGATTTGTATCATCGCCTGATAAATTGTGT & 60 \\
\hline 93 & CGAAATCCGCGACCTGCTCCATGTTACTTAGCCGGAACGAGGCGCAGACGGTCAATCATA & 60 \\
\hline 94 & AGGGAACCGAACTGACCAACTTTGAAAGAGGACAGATGAACGGTGTACAGACCAGGCGCA & 60 \\
\hline 95 & TAGGCTGGCTGACCTTCATCAAGAGTAATCTTGACAAGAACCGGATATTCATTACCCAAA & 60 \\
\hline 96 & TCAACGTAACAAAGCTGCTCATTCAGTGAATAAGGCTTGCCCTGACGAGAAACACCAGAA & 60 \\
\hline 97 & CGAGTAGTAAATTGGGCTTGAGATGGTTTAATTTCAACTTTAATCATTGTGAATTACCTT & 60 \\
\hline 98 & ATGCGATTTTAAGAACTGGCTCATTATACCAGTCAGGACGTTGGGAAGAAAAATCTACGT & 60 \\
\hline 99 & TAATAAAACGAACTAACGGAACAACATTATTACAGGTAGAAAGATTCATCAGTTGAGATT & 60 \\
\hline 100 & TAAGAGCAACACTATCATAACCCTCGTTTACCAGACGACGATAAAAACCAAAATAGCGAG & 60 \\
\hline 101 & AGGCTTTTGCAAAAGAAGTTTTGCCAGAGGGGGTAATAGTAAAATGTTTAGACTGGATAG & 60 \\
\hline 102 & CGTCCAATACTGCGGAATCGTCATAAATATTCATTGAATCCCCCTCAAATGCTTTAAACA & 60 \\
\hline 103 & GTTCAGAAAACGAGAATGACCATAAATCAAAAATCAGGTCTTTACCCTGACTATTATAGT & 60 \\
\hline 104 & CAGAAGCAAAGCGGATTGCATCAAAAAGATTAAGAGGAAGCCCGAAAGACTTCAAATATC & 60 \\
\hline 105 & GCGTTTTAATTCGAGCTTCAAAGCGAACCAGACCGGAAGCAAACTCCAACAGGTCAGGAT & 60 \\
\hline 106 & TAGAGAGTACCTTTAATTGCTCCTTTTGATAAGAGGTCATTTTTGCGGATGGCTTAGAGC & 60 \\
\hline 107 & TTAATTGCTGAATATAATGCTGTAGCTCAACATGTTTTAAATATGCAACTAAAGTACGGT & 60 \\
\hline 108 & GTCTGGAAGTTTCATTCCATATAACAGTTGATTCCCAATTCTGCGAACGAGTAGATTTAG & 60 \\
\hline 109 & TTTGACCATTAGATACATTTCGCAAATGGTCAATAACCTGTTTAGCTAT & 49 \\
\hline
\end{tabular}


Regions in bold indicate locations where detector strands are placed. Blue and green regions are single stranded extensions on detectors that are complementary to two halves of the input strands (color coded in target sequences). For nanoswitch construction and detector placement, refer to Figure S1.

\begin{tabular}{|l|l|c|}
\hline \multicolumn{3}{|c|}{ Variable sequences } \\
\hline \multicolumn{1}{|c|}{ Sequence } & \multicolumn{1}{|c|}{ Length } \\
\hline V1 & AACATCCAATAAATCATACAGGCAAGGCAAAGAATTAGCAAAATTAAGCAATAAAGCCTC & 60 \\
\hline V2 & GTGAGCGAGTAACAACCCGTCGGATTCTCCGTGGGAACAAACGGCGGATTGACCGTAATG & 60 \\
\hline V3 & TTCTTTTCACCAGTGAGACGGGCAACAGCTGATTGCCCTTCACCGCTTGGCCCTGAGAGA & 60 \\
\hline V4 & TCTGTCCATCACGCAAATTAACCGTTGTAGCAATACTTCTTTGATTAGTAATAACATCAC & 60 \\
\hline V5 & ATTCGACAACTCGTATTAAATCCTTTGCCCGAACGTTATTAATTTTAAAAGTTTGAGTAA & 60 \\
\hline V6 & TGGGTTATATAACTATATGTAAATGCTGATGCAAATCCAATCGCAAGACAAAGAACGCGA & 60 \\
\hline V7 & GTTTTAGCGAACCTCCCGACTTGCGGGAGGTTTTGAAGCCTTAAATCAAGATTAGTTGCT & 60 \\
\hline V8 & TCAACCGATTGAGGGAGGGAAGGTAAATATTGACGGAAATTATTCATTAAAGGTGAATTA & 60 \\
\hline V9 & GTATTAAGAGGCTGAGACTCCTCAAGAGAAGGATTAGGATTAGCGGGGTTTTGCTCAGTA & 60 \\
\hline V10 & AGCGAAAGACAGCATCGGAACGAGGGTAGCAACGGCTACAGAGGCTTTGAGGACTAAAGA & 60 \\
\hline V11 & TAGGAATACCACATTCAACTAATGCAGATACATAACGCCAAAAGGAATTACGAGGCATAG & 60 \\
\hline V12 & ATTTTCATTTGGGGCGCGAGCTGAAAAGGTGGCATCAATTCTACTAATAGTAGTAGCATT & 60 \\
\hline
\end{tabular}

\begin{tabular}{|l|l|c|}
\hline \multicolumn{3}{|c|}{ Detector sequences for characterization (4-8 loop size) } \\
\hline \multicolumn{1}{|c|}{$\#$} & \multicolumn{1}{|c|}{ Sequence } & Length \\
\hline V4 SP 40-15 & ACCGTTGTAGCAATACTTCTTTGATTAGTAATAACATCACTCACAATTAGATCCT & 55 \\
\hline V8 SP 15-40 & GTAACTTACACATGATCAACCGATTGAGGGAGGGAAGGTAAATATTGACGGAAAT & 55 \\
\hline V4 CF 40-12 & ACCGTTGTAGCAATACTTCTTTGATTAGTAATAACATCACGTCGTCTGCTGC & 52 \\
\hline V8 CF 12-40 & TGCTGCTGCTGCTCAACCGATTGAGGGAGGGAAGGTAAATATTGACGGAAAT & 52 \\
\hline V8 CF 11-40 & TGCTGCTGCTGTCAACCGATTGAGGGAGGGAAGGTAAATATTGACGGAAAT & 51 \\
\hline V8 CF 10-40 & TGCTGCTGCTTCAACCGATTGAGGGAGGGAAGGTAAATATTGACGGAAAT & 50 \\
\hline V8 CF 9-40 & TGCTGCTGCTCAACCGATTGAGGGAGGGAAGGTAAATATTGACGGAAAT & 49 \\
\hline V4 TS 40-11 & ACCGTTGTAGCAATACTTCTTTGATTAGTAATAACATCACGAACCGTATAT & 51 \\
\hline V8 TS 10-40 & CCTATGGCCCTCAACCGATTGAGGGAGGGAAGGTAAATATTGACGGAAAT & 50 \\
\hline V4 BRCA 40-13 & ACCGTTGTAGCAATACTTCTTTGATTAGTAATAACATCACCTTCCAACAGCTA & 53 \\
\hline V8 BRCA 12-40 & TAAACAGTCCTGTCAACCGATTGAGGGAGGGAAGGTAAATATTGACGGAAAT & 52 \\
\hline V4 HIV 40-12 & ACCGTTGTAGCAATACTTCTTTGATTAGTAATAACATCACAGTCAGTGTGGA & 52 \\
\hline V8 HIV 11-40 & AAATCTCTAGCTCAACCGATTGAGGGAGGGAAGGTAAATATTGACGGAAAT & 51 \\
\hline V4 WS 40-17 & ACCGTTGTAGCAATACTTCTTTGATTAGTAATAACATCACCATCTTCAAATCCATCT & 57 \\
\hline V8 WS 17-40 & TCTTTTCATTCCACTTTTCAACCGATTGAGGGAGGGAAGGTAAATATTGACGGAAAT & 57 \\
\hline
\end{tabular}




\begin{tabular}{|l|l|c|c|}
\hline \multicolumn{1}{|c|}{ Detector sequences for gene barcodes (different loop sizes) } \\
\hline \multicolumn{1}{|c|}{ Name } & \multicolumn{1}{|c|}{ Sequence } & 55 \\
\hline V4 SP 40-15 & ACCGTTGTAGCAATACTTCTTTGATTAGTAATAACATCACTCACAATTAGATCCT & 55 \\
\hline V5 SP 15-40 & GTAACTTACACATGAATTCGACAACTCGTATTAAATCCTTTGCCCGAACGTTATT & 52 \\
\hline V4 CF 40-12 & ACCGTTGTAGCAATACTTCTTTGATTAGTAATAACATCACGTCGTCTGCTGC & 52 \\
\hline V6 CF 12-40 & TGCTGCTGCTGCTGGGTTATATAACTATATGTAAATGCTGATGCAAATCCAA & 51 \\
\hline V4 TS 40-11 & ACCGTTGTAGCAATACTTCTTTGATTAGTAATAACATCACGAACCGTATAT & 50 \\
\hline V7 TS 10-40 & CCTATGGCCCGTTTTAGCGAACCTCCCGACTTGCGGGAGGTTTTGAAGCC & 53 \\
\hline V4 BRCA 40-13 & ACCGTTGTAGCAATACTTCTTTGATTAGTAATAACATCACCTTCCAACAGCTA & 52 \\
\hline V8 BRCA 12-40 & TAAACAGTCCTGTCAACCGATTGAGGGAGGGAAGGTAAATATTGACGGAAAT & 52 \\
\hline V4 HIV 40-12 & ACCGTTGTAGCAATACTTCTTTGATTAGTAATAACATCACAGTCAGTGTGGA & 51 \\
\hline V9 HIV 11-40 & AAATCTCTAGCGTATTAAGAGGCTGAGACTCCTCAAGAGAAGGATTAGGAT & 57 \\
\hline V3 WS 40-17 & GGCAACAGCTGATTGCCCTTCACCGCCTGGCCCTGAGAGACATCTTCAAATCCATCT & 57 \\
\hline V10 WS 17-40 & TCTTTTCATTCCACTTTAGCGAAAGACAGCATCGGAACGAGGGTAGCAACGGCTACA & 57 \\
\hline
\end{tabular}

\begin{tabular}{|l|l|c|}
\hline \multicolumn{3}{|c|}{ Detector sequences for mixed multiplexing barcodes (different loop sizes) } \\
\hline \multicolumn{1}{|c|}{ Name } & \multicolumn{1}{|c|}{ Sequence } & Length \\
\hline V4 dig & ACCGTTGTAGCAATACTTCTTTGATTAGTAATAACATCAC-dig & 40 \\
\hline V5 dig & dig-ATTCGACAACTCGTATTAAATCCTTTGCCCGAACGTTATT & 50 \\
\hline V4 RNA & ACCGTTGTAGCAATACTTCTTTGATTAGTAATAACATCACCGCCAATATTT & 52 \\
\hline V6 RNA & ACGTGCTGCTATGGGTTATATAACTATATGTAAATGCTGATGCAAATCCAA & 50 \\
\hline V4 DNA & ACCGTTGTAGCAATACTTCTTTGATTAGTAATAACATCACCCAACAACAT & 51 \\
\hline V7 DNA & GAAACTACCTAGTTTTAGCGAACCTCCCGACTTGCGGGAGGTTTTGAAGCC & 40 \\
\hline V4 biotin & ACCGTTGTAGCAATACTTCTTTGATTAGTAATAACATCAC-biotin & 40 \\
\hline V8 biotin & biotin-TCAACCGATTGAGGGAGGGAAGGTAAATATTGACGGAAAT & 51 \\
\hline V4 miR-30c & ACCGTTGTAGCAATACTTCTTTGATTAGTAATAACATCACTCCAACACTGT & 51 \\
\hline V5 miR-30c & ACTGGAAGATGATTCGACAACTCGTATTAAATCCTTTGCCCGAACGTTATT & 52 \\
\hline V4 miR-141 & ACCGTTGTAGCAATACTTCTTTGATTAGTAATAACATCACGCTGAGAGTGTA & 51 \\
\hline V7 miR-141 & GGATGTTTACAGTTTTAGCGAACCTCCCGACTTGCGGGAGGTTTTGAAGCC & 50 \\
\hline BB37 PSA1 & CAATCAATATCTGGTCAGTTGGCAAATCAA-ab1 & 30 \\
\hline V7 PSA2 & ab2-GTTTTAGCGAACCTCCCGACTTGCGGGAGG & 5 \\
\hline
\end{tabular}




\begin{tabular}{|l|l|c|}
\hline \multicolumn{2}{|c|}{ Filler sequences } & \multicolumn{1}{|c|}{ Sequence } \\
\hline \multicolumn{1}{|c|}{ Name } & & 20 \\
\hline V3 filler & TTCTTTTCACCAGTGAGACG & 20 \\
\hline V4 filler & TCTGTCCATCACGCAAATTA & 20 \\
\hline V5 filler & AATTTTAAAAGTTTGAGTAA & 20 \\
\hline V6 filler & TCGCAAGACAAAGAACGCGA & 20 \\
\hline V7 filler & TTAAATCAAGATTAGTTGCT & 20 \\
\hline V8 filler & TATTCATTAAAGGTGAATTA & 20 \\
\hline V9 filler & TAGCGGGGTTTTGCTCAGTA & 20 \\
\hline V10 filler & GAGGCTTTGAGGACTAAAGA & 30 \\
\hline BB37 filler (PSA) & CACCTTGCTGAACCTCAAATATCAAACCCT & 30 \\
\hline V7 filler (PSA) & TTTTGAAGCCTTAAATCAAGATTAGTTGCT & 20 \\
\hline
\end{tabular}

\begin{tabular}{|l|l|c|}
\hline \multicolumn{2}{|c|}{ Narget sequences } & \multicolumn{1}{|c|}{ Sequence } \\
\hline \multicolumn{1}{|c|}{ Name } & \multicolumn{1}{|c|}{ Length } \\
\hline SP DNA & TCATGTGTAAGTTACAGGATCTAATTGTGA & 30 \\
\hline CF DNA & GCAGCAGCAGCAGCAGCAGACGAC & 24 \\
\hline TS DNA & GGGCCATAGGATATACGGTTC & 21 \\
\hline BRCA1 DNA & CAGGACTGTTTATAGCTGTTGGAAG & 25 \\
\hline HIV1 DNA & GCTAGAGATTTTCCACACTGACT & 23 \\
\hline WS DNA & AAAGTGGAATGAAAAGAAGATGGATTTGAAGATG & 34 \\
\hline CF 1 mismatch & GCAGCACCAGCAGCAGCAGACGAC & 24 \\
\hline CF 2 mismatch & GCTGCACCAGCAGCAGCAGACGAC & 24 \\
\hline CF 3 mismatch & GCTGGACCAGCAGCAGCAGACGAC & 24 \\
\hline RNA (Fig 4) & UAGCAGCACGUAAAUAUUGGCG & 22 \\
\hline DNA (Fig 4) & TAGGTAGTTTCATGTTGTTGG & 21 \\
\hline miR-141 DNA & CATCTTCCAGTACAGTGTTGGA & 22 \\
\hline miR-30c DNA & TGTAAACATCCTACACTCTCAGC & 23 \\
\hline miR-141 RNA & CAUCUUCCAGUACAGUGUUGGA & 22 \\
\hline
\end{tabular}

\begin{tabular}{|l|l|c|}
\hline \multicolumn{2}{|c|}{ Other strands } & Length \\
\hline \multicolumn{1}{|c|}{ Name } & \multicolumn{1}{|c|}{ Sequence } & 22 \\
\hline Blocking oligos & ACGGTCTCATGGCCCTTCAATC & 40 \\
\hline BtsCl cut site oligo & CTACTAATAGTAGTAGCATTAACATCCAATAAATCATACA & 40 \\
\hline
\end{tabular}

